\title{
st \\ Ciencia, tecnología y ética en los orígenes de la ciencia moderna: \\ el caso de Jonathan Swift \\ Guillermo Boido
}

\section{INTRODUGGIÓN}

La conocida y despiadada sátira que Jonathan Swift (1667-1745) destinó a las instituciones científicas de su época puede ser considerada como la primera manifestación crítica sistemática a la nueva ciencia europea, por entonces en desarrollo, y particularmente a sus supuestas y jactanciosas aplicaciones. El irlandés Swift, hombre de dos mundos, Inglaterra e Irlanda, fue testigo de innumerables calamidades políticas y bélicas, de cuanta muestra de corrupción, superficialidad y arrogancia dominaba la escena pública inglesa de su época, de la condición infrahumana en la que estaban sumidos sus desposeídos compatriotas. Dio cuenta de ello, sin tapujos, en innumerables páginas satíricas, a veces de una tensión insoportable, que no tienen parangón en la historia de la literatura inglesa y quizás universal, y destinó algunas de sus diatribas más lapidarias a las arrogantes pretensiones de las instituciones de la ciencia de su tiempo y en particular las de la Royal Society. Su carácter de cristiano practicante y ministro anglicano no le impidió escribir: "Tenemos bastante religión para hacernos odiar, pero no la suficiente para hacer que nos amemos los unos a los otros". Su azarosa vida lo convirtió, en su vejez, en un misántropo sin remedio. Pero veamos de qué modo expresa Swift sus críticas a la actividad científica de entonces y, en ese contexto, analicemos la pertinencia de las mismas. Por razones de tiempo, nos remitiremos exclusivamente a las afirmaciones que pone en boca de su inmortal personaje, el capitán Gulliver, en el transcurso de dos de los remotos países que visita.

\section{Gulliver en Laputa y Balnibarbi}

Swift publicó su libro Viajes por diversos países remotos del mundo (conocido hoy simplemente como Los viajes de Gulliver) en 1726, un año antes de la muerte de Newton. 
El capitán Gulliver es rescatado de un inhóspito paraje en el que se ha refugiado luego de que su navío fuese capturado por piratas, por los habitantes de una enorme isla voladora. Allí se encuentra el reino de Laputa, que constantemente se mantiene en las alturas y ejerce dictatorialmente el control político sobre el país continental de Balnibarbi. La referencia a Inglaterra e Irlanda es manifiesta. Swift, quien conocía bastante bien el castellano, al igual que su personaje, tildó en más de una ocasión de prostituta a Inglaterra. En Laputa predomina el cultivo de la matemática, que se corresponde con el creciente interés de la época por las obras de Descartes, Galileo, Leibniz y Newton, este último ya deificado en Inglaterra en la época en que Swift publicó sus Viajes. La nueva ciencia newtoniana era recibida con beneplácito por gobernantes y teólogos porque mostraba la existencia en la naturaleza de un orden establecido y guiado por la providencia divina, lo cual legitimaba a su vez la necesidad de armonía y estabilidad social que sólo podían garantizar la monarquía y la Iglesia. La conexión entre matemática y música, la otra afición de los habitantes de Laputa, refleja la convicción, en tiempos de Swift, de que cada una a su modo expresaba la perfección de verdades eternas.

Los intereses de los laputenses son enteramente teóricos; ignoran cuanto atañe al mundo cotidiano, al testimonio de los sentidos y a las cuestiones prácticas. De allí que las viviendas de Laputa sean desastrosas, pues las indicaciones que se dan a los obreros, por demasiado abstractas, son incomprensibles para ellos. Los laputenses tienen un ojo vuelto hacia adentro y el otro dirigido hacia el cenit porque se hallan completamente absorbidos en sus meditaciones matemáticas y en el estudio de los astros, lo cual obliga a los pudientes a disponer de la asistencia de un sirviente, el sacudidor, para impedir que caigan en un precipicio o choquen contra un poste cuando transitan por la calle. La belleza de una mujer es descrita con el recurso a rombos, círculos, paralelogramos o elipses, y los alimentos se presentan en la mesa tallados en forma de figuras geométricas, tales como cilindros y conos. Maliciosamente, Swift hace decir a Gulliver que las mujeres de los laputenses, mientras éstos se hallan sumidos en sus profundas reflexiones, otorgan sus favores sexuales a los extranjeros incluso en presencia de sus maridos.

Conducido Gulliver al devastado y sojuzgado país continental de Balnibarbi, se lo lleva a su capital, Lagado, y allí se le permite visitar la Academia de Proyectistas, cuya fecha de fundación, y no por azar, Swift hace coincidir aproximadamente con la de la Royal Society. Allí los científicos se empeñan en llevar a cabo tareas tales como la extracción de la luz de los pepinos para ser almacenada y empleada durante el invierno, el ablandamiento del mármol para la fabricación de almohadas, la reconversión de excrementos humanos en el alimento original o el reemplazo de los gusanos de seda por arañas, porque, como se le explica a Gulliver, ellas no sólo producen el hilo sino que además saben tejer. Este proyectista confía en que, alimentadas con moscas de colores 
diversos, las arañas habrán de producir tejidos igualmente coloridos. Mientras un arquitecto desarrolla el proyecto de construir edificios comenzando por el tejado, otro investigador se halla abocado a la obtención de fármacos destinados a combatir la corrupción de los gobiernos y de la administración pública. En la sección de Artes y Ciencias Sociales, el viajero encuentra a los diseñadores de una "máquina literaria" destinada a producir secuencias de palabras al azar, de tal modo que, con ella, como se le dice a Gulliver, "la persona más ignorante será, por un precio módico y con un pequeño esfuerzo muscular, capaz de escribir libros de filosofía, poesía, política, derecho, matemática y teología sin precisar genio ni estudio". Gulliver recoge también algunas sugerencias para simplificar la lengua a fin de perfeccionarla, tales como el proyecto de suprimir todas las palabras sustituyéndolas por cosas.

\section{Swift: ¿ignORANTE EN GUESTIONES GiENTÍficas?}

Sería fácil desprestigiar la sátira de la ciencia de Swift, al fin de cuentas un hombre de letras, tachándolo de desinformado y reaccionario. Pero esta valoración superficial olvida un punto crucial: Swift se hallaba muy bien informado en cuestiones científicas y conocía de primera mano el funcionamiento de las instituciones inglesas; por otra parte, no dejó de pronunciarse acerca de los valores positivos de la investigación científica. A modo de ejemplo, señalemos que aprobó con entusiasmo El avance del conocimiento, de Bacon. Estuvo en contacto con hombres de ciencia desde su juventud, y su amigo más apreciado, el doctor Arbuthnot, médico de la reina Ana Estuardo y miembro de la Royal Society, denunció al igual que él la pedantería de los falsos científicos. Los trabajos reales de los científicos son la base de la crítica de Swift, como sabemos desde que en 1937 una especialista en literatura, Mary Nicolson, y una física profesional, Nancy Mohler, y luego otros, en particular Isaac Asimov, pusieran en evidencia que los experimentos a los que asiste Gulliver en la Academia de Lagado están, en buena medida, basados en los informes que se publicaban en las Actas de la Royal Society. Pero ellas no son las únicas fuentes en las que se inspiró Swift. Digamos, por caso, que el fundamento científico del modo en que opera la isla flotante donde se encuentra Laputa radica en el magnetismo, y que el conocimiento acerca de la cuestión fue obtenido por Swift del libro Sobre los imanes, de William Gilbert, y también de la "filosofía magnética" del jesuita Athanasius Kircher. Por otra parte, Gulliver menciona la ley de gravitación de Newton y la tercera ley de Kepler con pleno dominio del tema, a la vez que se extiende en consideraciones matemáticas, astronómicas y geodésicas que revelan un conocimiento en modo alguno superficial de tales materias. 


\section{SÁtIRA Y REALIDAD}

Ahora bien, ¿merecían los proyectos acogidos por la Royal Society el tratamiento satírico que Swift les destina? Uno de los episodios más memorables (e hilarantes) que narra Gulliver en su visita a la Academia de Lagado se refiere al experimento realizado con un perro, destinado a lograr la cura de los cólicos. Un famoso médico introduce aire con un fuelle por el ano del perro, lo cual repite varias veces "para dejarle las tripas tan huecas como una vejiga seca". Hecho el experimento, el perro suelta una violenta descarga de aire y muere en el acto. Consideremos ahora la realidad, ejemplificada por ciertos informes presentados a la Royal Society, como un estudio de Stephen Hales, el célebre químico y fisiólogo británico, de 1726. Aquí se describen experimentos un tanto bizarros para probar que la luz se almacena en los vegetales (aunque no se mencionen pepinos) y otros efectivamente realizados con un perro en donde al pobre animal, sin orden ni concierto, se le corta la tráquea, se le inyecta aire en ella etc. En otro trabajo presentado por el francés Maurice Bon (1710), llamado precisamente "La seda de las arañas", el objetivo es similar al del proyectista de Lagado. La propuesta venía acompañada de diseños de una serie de prendas, tales como guantes, que podrían ser tejidas con hilos de araña. Otro proyecto, de cierto Dr. Wall (1708), consiste en alimentar a hormigas con la savia coloreada de diversos vegetales para que sus excrementos se convirtiesen en colorantes de tejidos. (Recuérdense las moscas de colores para alimentar arañas ...) Como escriben Nicolson y Mohler, Swift "puso delante de sus lectores experimentos realmente llevados a cabo por miembros de la Royal Society, más absurdos para el lego que cualquier cosa que la imaginación pudiera inventar y más devastadores en su sátira a causa de su fidelidad esencial a las fuentes" (Nicolson \& Mohler, 1937, p. 228).

¿Dónde termina el experimento real y comienza la sátira? Considerando los módicos logros prácticos de la ciencia en tiempos de Swift y muchos de los descabellados experimentos que se describían en las Actas de la Royal Society, ¿tendremos derecho a considerar a Swift como un reaccionario enemigo de la ciencia? La ciencia había hecho bien poco para mejorar las condiciones de vida: los prometidos valores utilitarios del conocimiento científico que impulsaba la Sociedad brillaban por su ausencia. Los "modernos" presentaban orgullosamente como prueba de superioridad frente a los "antiguos" el más importante fruto de la ciencia aplicada en tiempos de Swift: el perfeccionamiento de la pólvora y el mejoramiento de las armas de fuego. En el Segundo Viaje, Gulliver ofrece al pacífico rey de Brobdingnac pormenorizarle la forma de obtener el explosivo y una detallada descripción de los efectos de armas tales como esferas rellenas con pólvora que al estallar "hacen saltar los sesos del que encuentre a su paso". El rey, horrorizado, rechaza la propuesta, pues no puede comprender que alguien "pu- 
diera albergar ideas tan inhumanas y que lo hiciera con tanta naturalidad sin mostrar ningún tipo de afectación ante escenas de tanta sangre y desolación". La medicina, pese a los esfuerzos de la Royal Society, hacía bien poco para la cura de las enfermedades; y los médicos, más que prolongar la vida, parecían empeñados en acortarla con la administración de absurdos brebajes a sus pacientes sin el menor conocimiento de la naturaleza de las enfermedades. Swift satiriza las brutales prácticas empleadas por los cirujanos ingleses en su memorable descripción de los procedimientos utilizados por sus colegas de Lagado, quienes bisecan los cerebros de miembros de partidos políticos rivales y los unen por mitades "para que dialoguen en un mismo cráneo". En Inglaterra, azarosos experimentos realizados por agrónomos provocaban el agotamiento de las tierras y la matematización de la economía que se intentaba realizar por entonces no conducía más que a meras especulaciones sin provecho alguno para el mejoramiento de la situación humana.

Swift ataca además la novísima y absoluta visión cuantificada del mundo, lo cual conduce a su juicio a una ciencia que identifica la realidad con sus formalizaciones matemáticas. Aunque su artillería mayor en contra de todo ello se encuentre en el tercer viaje de Gulliver, la hallamos también, por caso, en el texto satírico breve más difundido y sin duda uno de los más devastadores que se hayan escrito jamás: Una modesta proposición (1729). Escrita en momentos en que una terrible hambruna asolaba Irlanda, y poseído Swift por la más absoluta desesperación, la propuesta, como es sabido, es convertir a los niños pobres de un año en ganado para alimentar a los ricos. Si la proposición en sí misma es atroz, no lo es menos el frío y "objetivo" argumento al que recurre Swift, redactado en los términos habituales de los informes a la Royal Society, y cuya persuasión pretende conducir inexorablemente a la aceptación de que es conveniente para todos (pobres, ricos, gobierno, Iglesia, administración, justicia etc.) adoptar tal medida. Asumiendo el papel de "proyectista”, Swift denuncia los intentos de matematizar la política y la economía para hacernos llegar a la conclusión de que el canibalismo es conveniente y necesario para resolver los problemas sociales de Irlanda.

\section{4 ¿A quiénes ataga Swift?}

La Academia de Lagado no es otra cosa que la contraparte satírica de la "Casa de Salomón", el baconiano templo del conocimiento divino dedicado a la liberación del estado del hombre y a la restauración milenarista de la perfección, que expresa la confianza de Bacon en la ciencia y la técnica como instrumentos para acceder al mejoramiento de la condición humana. La Royal Society intentaba llevar a cabo tan elevado proyecto, pero éste, en la mordaz apreciación de Swift, lejos de hallarse en vías de con- 
creción, se había extraviado en quimeras, especulaciones, charlatanerías e insensatos experimentos que poco tenían que ver con lo estrictamente científico ni sus resultados con la satisfacción de necesidades humanas. Por el contrario, como escribe Kathleen Williams, "los proyectos de Lagado se desarrollan en una atmósfera de actividades sin metas, de valores distorsionados y de una perversión del sentido de las cosas hasta el punto de despojar de ellas toda vida y significado. El resultado produce ovejas sin lana, perros muertos, caballos cuyas pezuñas se han transformado en piedra" (Williams, 1958, p. 173). Swift logra así transmitir el modo en que los proyectistas subvierten el precepto baconiano de que la naturaleza, si ha de ser dominada, ha de ser previamente respetada, y cita aquél célebre aforismo del Novum organum según el cual el hombre ha de ser servidor e intérprete de la naturaleza. Pero también denuncia la mera recolección de datos y experimentos sin propósito que produjo el baconianismo aplicado a ultranza. Por todo ello, a juicio de Swift, la aspiración de Bacon de que las invenciones técnicas, al mejorar las condiciones de vida, habrían de devolver al hombre a un adánico paraíso perdido, se había extraviado sin remedio. Sin duda, Swift está más interesado en las implicancias sociales, morales y políticas de las teorías científicas que en ellas mismas, y considera que la ciencia especulativa de Laputa es estéril porque no es utilitaria, mientras que en Lagado, a la inversa, la búsqueda de conocimiento útil se canaliza por medio de absurdos experimentos cuyos resultados son desastrosos.

\section{Conalusiones}

El embate de Swift no está dirigido contra la ciencia misma, sino contra las prácticas que bajo el falaz rótulo de "ciencia" encubrían formas diversas de palabrería, petulancia, pretensiones desmedidas, extravagancias y seudociencia. En modo alguno puede ser concebido como un enemigo de la auténtica ciencia. Ya hemos señalado que aprobaba sin tapujos el programa utilitarista de Bacon, cuya corrupción y descarrío denunciaba. Escribió, con palabras que atribuye al rey de Brobdingnag, que la ciencia es de mayor utilidad que la política: “quien pudiera hacer crecer dos espigas de grano o dos briznas de hierba en un trozo de terreno donde anteriormente sólo crecía una, merecería el agradecimiento de la humanidad y haría un servicio más substancial a su país que toda la casta de políticos juntos". De haber adherido Swift al optimismo de la Ilustración, quizás hubiese podido advertir en mayor medida todo aquello que razonablemente la ciencia podría hacer en el futuro por el mejoramiento de la situación humana. Pero era Jonathan Swift, y no pudo (ni quiso) dejar de testimoniar su compasión por un mundo sufriente ni denunciar a los poderes capaces de devastar al ser humano 
bajo el estandarte del "progreso". No podía, por tanto, aprobar la proclamada y no todavía comprobada certeza de los cultores de la recién nacida nueva ciencia en cuanto a sus poderes redentores de la condición humana.

El viaje a Laputa y Balnibarbi es una forma temprana de ciencia ficción en la tradición pesimista que habrían de encarnar más adelante las obras de Wells o de Orwell. Pues Swift señaló claramente el riesgo de depositar una exagerada fe en las posibilidades liberadoras de la ciencia, al margen de cuánto hipotéticamente podía esperarse de ella para el mejoramiento de la sociedad. Percibió, mucho antes de que otros lo hicieran, la dualidad y ambivalencia de los usos del conocimiento para la prosperidad o bien para la degradación de la humanidad, es decir, la conexión de los problemas de la filosofía natural con los de la filosofía moral. La gran metáfora que nos presenta en el Tercer Viaje consiste en que la tecnología que ha permitido construir la isla voladora acaba siendo a la vez el instrumento por medio del cual los laputenses oprimen políticamente al reino de Balni-

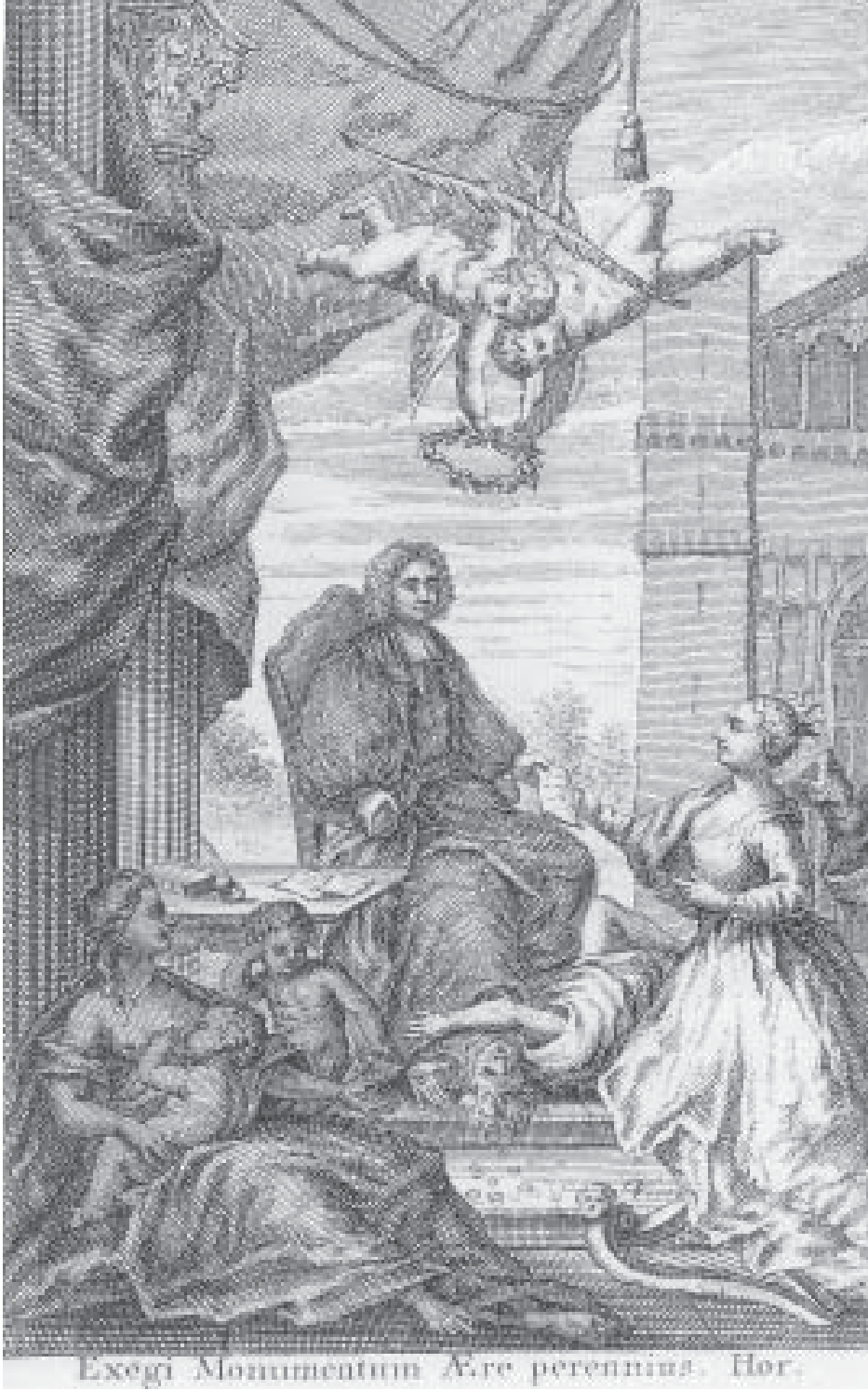

Frontispício à edição de ${ }_{1}{ }_{3} 5$ das Obras de Jonathan Swift, no qual ele recebe o agradecimento da Irlanda. A inscrição latina de Horácio diz: "Fiz um monumento mais perene que o bronze".

barbi. Swift insistió muchas veces en que el ser humano debía ser razonable, y que sus esfuerzos debían a la vez ser útiles y amparados por un sentido moral, pero halló muy poca utilidad y moralidad en la ciencia de su tiempo. En el mismo sentido, Pilar Elena destaca que, en la Academia de Lagado, Swift satiriza una manifestación del capitalismo de principios del siglo xviı, la aparición de estos "proyectistas": "La especulación ya no es aquí la reflexión 'etérea' de los laputenses, sino la actividad que persigue una rentabilidad económica: los proyectistas de Lagado no ponen en manos del Estado sus inventos, sino que esperan de ellos el beneficio económico individual, y sus proyectos, como ocurría en la realidad, abarcan los más diversos campos, desde las ciencias na- 
turales y las técnicas aplicadas, a la economía y la política" (Elena, 2000, p. 109). En síntesis, Swift no estuvo dispuesto a separar las consideraciones morales de las abstracciones, de los dudosos logros y de las condiciones de la producción científica de su época. Tal separación, a su juicio, podría desembocar en catástrofes irremediables.

Y es innecesario señalar que el tiempo le ha dado la razón.๑

\section{Guillermo Boido}

Profesor de la Facultad de Ciencias Exactas y Naturales, Universidad de Buenos Aires, Argentina. Asociación de Filosofía e Historia de la Ciencia del Cono Sur (AFHIC). gboido@mail.retina.ar

\section{REFERÊNGIAS BIBLIOGRÁFIGAS}

Elena, P. Introducción y notas. In: Swift, J. Los viajes de Gulliver. Traducción P. Elena. Madrid: Cátedra, 2000.

Nicolson, M. \& Mohler, N. M. The scientific background of Swift's voyage to Laputa. Annals of Science, 2, p. $211-45,1937$.

Swift, J. Los viajes de Gulliver. Traducción P. Elena. Madrid: Cátedra, 2000.

Williams, K. Jonathan Swift and the age of compromise. Lawrence, s. n., $195^{8}$.

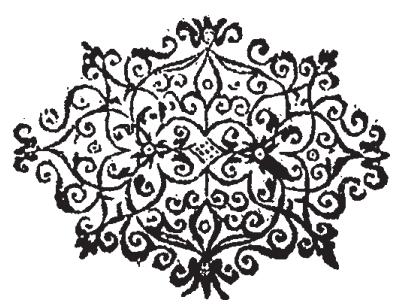

